\title{
The Nordic model of taxation and its influence in North America: Image and Reality
}

DOI 10.1515/ntaxj-2016-0008

Received Aug 23, 2016; accepted Oct 25, 2016

\section{Introduction}

The idea of a Scandinavian or Nordic model in public policy has a long history. Scholars usually trace the idea to a book "Sweden: The Middle Way" written by journalist Marquis Childs in the 1930s. Childs argued that the Swedish system, which combined private ownership of most productive assets with a generous welfare state and relative labor peace, lay somewhere between and was arguably preferable to American-style capitalism, on the one hand, and a Soviet-style socialism, on the other hand. Numerous authors have picked up on similar themes over the years, frequently expanding the analysis to include Denmark, Norway, Finland, and sometimes Iceland as well, and increasingly citing social and cultural policy - environmentalism, women's rights, and an innovative, can-do spirit - as well as the more traditional economic aspects. A recent book, “The Nordic Theory of Everything” (Partanen (2016)), takes the analysis a step further, arguing that Finland and its neighbors are superior to other countries (especially the United States) in virtually every way.

Taxes, and tax policy, fit uneasily into these accolades. Nordic taxes are high, and most people do not like high taxes. Yet the argument has been made that Nordic tax systems are actually better than those in other countries for one of the several reasons: because they are not as high as they first appear, because they pay for benefits that exceed their cost, or because they are administered in such a fair and painless way that people actually enjoy paying them. These arguments are not mutually exclusive, but rather complementary in nature, and they appear to have convinced many people, although perhaps more so outside the Nordic countries than within them.

${ }^{\star}$ Corresponding Author: Michael A. Livingston: Rutgers Law School; Email: weissliv@comcast.net
This article considers the Nordic model of taxation and its influence outside the Nordic region, particularly in North America. Section 1 considers the Nordic model and its history. Section 2 considers some facts about Nordic tax systems and a few of the principal debates about those systems. Section 3 considers the degree to which Nordic taxation constitutes a useful model for other countries and the related but distinct question of whether it is actually used as a model. Section 4 presents some broader reflections on the Nordic experience and its implications for the study of comparative tax law and the globalization problem.

Throughout the article, I will refer to the "Nordic region," "Norden," and (less frequently) "Scandinavia” as a single unit, typically including all of the countries above together with smaller entities (e.g., the Faroe Islands) that share basic characteristics with it. I recognize that this is a fiction, because the countries involved vary considerably in tax and nontax policy, and that Scandinavia in particular is an inaccurate, confusing word. Nevertheless, the terms remain prominent in policy discourse, and indeed, the lumping of the Nordic countries together has become a powerful tool in marketing (some would say falsely marketing) the Nordic model outside the region. Readers uncomfortable with these terms should feel free to substitute "the so-called Nordic countries," "Sweden and its neighbors," or "the countries lying north of Germany, west of Russia, and somewhere northeast of Great Britain” at appropriate points in the text.

\section{The Nordic Model and Its (Surprisingly) Persistent Appeal}

The concept of the Nordic model is usually dated to the 1930s when Marquis Childs, a Midwestern journalist and not especially successful fiction author, published "Sweden: The Middle Way," one of the three books in which he lauded that country for achieving a proper balance between social justice and economic viability (Childs (1936)). Childs was especially impressed by the use of cooperative enterprises in the Swedish economy. The book received a 
significant boost when it was mentioned at a press conference by President Franklin D. Roosevelt, who sent a commission to Europe to study the use of cooperatives and their implications for the United States. Childs later became somewhat more conservative, expressing concern about the concentration of power and its corrupting influence, although this did not prevent him from receiving a medal from the King of Sweden in 1961.

The interest in the Nordic countries continued to grow after World War II, although less as an alternative to communism, which was largely discredited by the 1950s, and more as an alternate form of Western-style, capitalist development. This interest was particularly strong on the British and American left, which sought to refute the argument that "socialism" or the "welfare state" must inevitably result in political dictatorship, economic stagnation, and moral or cultural bankruptcy. The Nordic countries, which were relatively wealthy and appeared to be politically and culturally robust, seemed to refute these arguments. The admiration was now spread among Sweden, Denmark, Norway, and later, Finland, although it seems fair to say that Sweden remained most prominent, both for its actual accomplishments and because foreigners often confused the Nordic countries, assuming in particular that prominent Norwegians (Liv Ullman, ABBA's Anni-Frid Lyngstad) were actually Swedish in origin.

What precisely constitutes the Nordic model is the subject of some debate. Scholars typically have emphasized three elements: (i) continued private ownership of all or most productive assets; (ii) creation and maintenance of a universal welfare state, in which education, health care, retirement, and other basic services are either provided or paid for by the state, typically without regard to the recipient's economic status; and (iii) the maintenance of labor peace by the negotiation of contracts at the national level and a broad pattern of cooperation between unions and management interests. As time has passed, the third of these elements has become less important and appears to have been replaced by something that could be described as "a high degree of political consensus with the social democrats either remaining in power or replaced by parties that share their original program."

Although not all these elements are present in all countries at all times, they appear consistently enough (especially items i and ii) to constitute a coherent model and be perceived as such in other European and non-European countries.

While academics emphasize economic and social policy, Nordic countries are also identified with various behavioral or cultural traits, including a high degree of women's equality, progressive environmental policy, and a culture of innovation, especially in design and high technology (high-tech) (Hilson (2008)). Although these concerns are genuine, they have also been marketed very aggressively, with locally based corporations emphasizing features such as automobile safety (Volvo), natural or "functional" design (Dansk or Marimekko), consumeroriented high-tech (Skype, Spotify, Nokia), creative children's play (Lego, Minecraft), and natural or unprocessed foods (the specialty coffee industry) that present an image of modern, healthy, and humane living that is especially attractive to younger consumers. Nordic foreign policy, especially in Norway and Sweden, likewise emphasizes human rights and development assistance and constitutes an additional form of marketing for the countries involved. Books, movies, and other cultural output contribute further to this image. Whether and to what degree these elements constitute part of the Nordic model is an interesting question, but they unquestionably affect the perception of the Nordic countries and the attractiveness of their political and social systems.

In recent years, the Nordic model has faced serious challenges, including fiscal pressures; increasing immigration, which threatens to undermine both the economic and cultural foundations of the model; and the collapse of the Soviet Union, which undermines the claim to be a "middle way" between competing extremes. These and other factors have led to substantial policy changes, notably in Sweden, and (by Nordic standards) a high degree of political instability. In my personal interviews, Nordic scholars have frequently spoken of the model in the past tense.

While the model faces challenges at home, its overseas appeal appears to be undiminished and even to have increased in stature. Bernie Sanders, a candidate for US President, was quoted as saying that we should look to "countries like Denmark, like Sweden and Norway, and learn what they have accomplished for their working people." Books and articles about the model appear at a prodigious rate, including Scott (2014); Brandal et al. (2013); Kvist et al. (2012); Hilson (2008) although some are mildly ironic in nature (Booth (2016)), while the appetite for Nordic consumer products is strong and growing. How much of this fascination is attributable to Nordic reality and how much to a fantasy promoted by the Nordic countries themselves - or frustration with Anglo-American political reality - remains an open question. One way or another, it appears that the Nordic model will be with us for the foreseeable

\footnotetext{
$1 \mathrm{http://www.cnn.com/2016/02/17/politics/bernie-sanders-2016-}$
} denmark-democratic-socialism/ 
future and will continue to influence the political debate for many years to come.

\section{Nordic Tax Systems: High and Fair, or Just Plain High?}

The Nordic welfare states are funded by taxes that, at least on paper, are some of the highest in the world. According to data compiled by a nonpartisan foundation, the highest individual income tax rate in 2015 (including mandatory payroll contributions) was about $60 \%$ in Denmark, $57 \%$ in Sweden, and $39 \%$ in Norway, compared to $46 \%$ in the United States. While these taxes are nominally progressive, the maximum or near-maximum rates are reached at relatively modest levels of income, so that the taxes paid by an average Danish, Swedish, or even Norwegian taxpayer are substantially higher than that would be the case in the United States or other western nations. ${ }^{2}$

Nobody likes to pay taxes, so high tax rates are Exhibit One for critics of the Nordic model both at home and abroad. Against this criticism, three principal arguments are mustered. The first is that one must look at the overall tax system rather than only the individual income tax. Indeed, while the Nordic countries have high individual taxes, both their corporate income and capital gain tax rates tend to be much lower, in many cases are below the equivalent rates in the United States and other western countries. ${ }^{3}$ This situation results in large part from practical considerations, specifically the need to stay competitive in export-driven economies. Whether lower business taxes make high individual tax rates easier or harder to stomach - I would personally find it harder - it is true that the aggregate Nordic tax bite is less than initially appears.

A second argument relates not to taxes but to benefits. Sure, it is said that Nordics pay high taxes but look what we

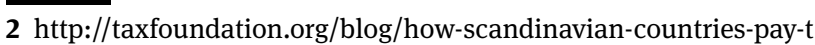
heir-government-spending (July 11, 2016) The top rate in Finland was just more than $50 \%$. These same countries also have relatively high (24\% Finland, 25\% for the remaining countries) value-added taxes (VATs). The United States does not have a VAT, although some states have sales and use taxes. Benefit formulas make the overall Nordic systems, including taxes and benefits, either more or less progressive than appears from taxes alone.

3 The Tax Foundation reports marginal corporate tax rates of $22 \%$ in Sweden and 24.5\% in Denmark as opposed to a 39\% nominal rate in the United States (State and Federal). Sweden in particular has no wealth, inheritance, or property taxes, and its overall taxes on wealth owners are much lower than they used to be (Henrekson and Jakobsson (2001)). get for them: free or heavily subsidized education, health care, retirement savings, and (depending on the country) parental leave, child care, and other benefits. Some observers have suggested that when the value of these benefits is backed out, Nordic taxes are no higher and may actually be lower than those in the United States or other countries, where people must pay separately for each of the relevant benefits. This is sometimes combined with the argument - not entirely unconvincing - that Nordics have a more developed sense of community and civic obligation than exists in other countries. Taking this argument a step further, Anu Partanen in "The Nordic Theory of Everything" suggests that Nordics benefit from greater freedom than Americans, because they are free from the worries of illness, old age, and so forth and accordingly less encumbered in their choice of jobs, spouses, and other important life decisions (Partanen (2016)).

The benefits argument is convincing on many levels, but it relies on certain assumptions. The obvious problem is that one may not want precisely the kinds of benefits that the Nordic Governments provide, preferring to spend money, for example, on one's own home, church, or family than on government-provided education, health care, and so forth. The high tax, redistributive model relies on a nearly universal participation of both men and women in the labor force, which some may find unattractive, and (arguably) on a high degree of ethnic and social homogeneity (Alesino et al. (2001); Dahlberg (2012)) (These are two of the reasons that the Nordic countries have had a hard time assimilating immigrants from traditional societies.) Finally, and most obviously, the model assumes a large degree of redistribution between classes and regions, an arguably manageable issue for small countries but far more problematic for larger, more diverse nations. All this is another way of saying that the Nordic approach involves a series of political and ideological choices, and Nordic taxes are an important part of this equation.

In addition to the business and benefits arguments, defenders of Nordic taxes sometimes make a third argument relating to tax administration. This argument suggests that while tax rates remain high, the perceived quality and fairness of Nordic tax agencies somewhat cushions the blow, so that there is relatively little of the antitax feeling prevalent in other countries. This is sometimes coupled with the more hard-headed argument that Scandinavian society, with its high degree of organization and reliance on computerized transactions, makes taxes difficult to avoid even if one should wish to. Several of the Nordic tax agencies have recently adopted a "service" rather than "enforcement" orientation, including retraining of personnel and a high level of computer sophistication, which ar- 
guably enhances both of these phenomena. The administrative argument is significant, because it suggests techniques and approaches that might be exportable to other countries, even if "Nordic culture" or social attitudes were to a degree unique in nature. We will consider this argument in greater detail below.

In addition to the usual income, excise and VATs, the Nordic countries have experimented with the so-called environmental taxes, that is, taxes that are designed to reduce energy consumption as well as raising revenue. Sweden's koldioxidskatt (carbon dioxide tax), which is imposed at a rate of 125 Euros/ton with reductions for industrial use and electricity generation, is the best known, although Denmark, Norway, and Finland have all introduced similar taxes. ${ }^{4}$ Taxes of this nature are of course only one small part of environmental policy: the country also has biofuel buses, energy-efficient streetlights, and a comprehensive recycling program, and a network of signs throughout Stockholm say "thank you for using public transportation" (kollektivtrafik). But the willingness to use taxes among other policy instruments is noteworthy and is yet another factor distinguishing the Nordic tax systems from others in the industrialized world. ${ }^{5}$

\section{The Influence of the Nordic Model: Academics, Politics, and Specific Tax Issues}

When one speaks of a "Nordic Model," it implies not only a distinct way of doing things but an influence on other countries and regions. It is useful to make two distinctions here: between intellectual and political influence, on the one hand, and between tax and nontax issues, on the other hand. It may likewise be useful to distinguish between the reality of Nordic life and an image, even fantasy, of that life which has become popular in the past few decades, and which sometimes affects intellectuals no less (and arguably more than) the general public. We consider these issues in turn.

\footnotetext{
4 Sweden's environmental policies are promoted aggressively overseas. See Government of Sweden, "Sweden Tackles Climate Change," https://sweden.se/nature/sweden-tackles-climate-change/ (Aug. 1, 2016) (full-color, English-language brochure describing Sweden's efforts to reduce its carbon footprint).

5 Denmark, Norway, and Finland also impose the so-called "sugar taxes”(in practice, taxes on sugary beverages and related products) and Sweden is considering a similar levy.
}

\subsection{Intellectual Influence: The Nordic Model and the Anglo-American Left}

The appeal of the Nordic model to intellectuals rests on its apparent resolution of the contradiction between social justice and economic prosperity. In the 1930s, this expressed itself as an alternative to Soviet communism, which even many leftists recognized to be repressive in nature and which was further discredited by the purge trials and (in 1939) the Nazi-Soviet pact. (Rom-Jensen (2015)) Today, it is more likely to be seen as an alternative to unrestrained capitalism, as represented by the United States and to a lesser degree Great Britain, which many on the left believe to be fatally flawed by economic inequality and social injustice. While these differences relate primarily to economic and social policy, there is a cultural component to the Nordic model, including elements such as women's rights, environmentalism, and a perceived tolerance for diverse lifestyles, whose appeal equals and sometimes exceeds that of its more traditional elements from which they evolved (Anderson (2009); Marklund and Petersen (2013)).

As one might expect, intellectuals who are enamored of the Nordic model tend to emphasize the benefits provided rather than the taxes that pay for them. Indeed, high taxes form a central part of the counternarrative - that of a Nordic dystopia characterized by oppressive governments, grim and conformist citizens, and high suicide rates - that has been advanced by some conservative observers. But high taxes have not deterred foreign admirers and may, indeed, be a perversely attractive feature, especially for those resentful of the "one percent" that is said to dominate economic life in less progressive countries. Part of this appeal may result from a misunderstanding of Nordic taxes, which are assumed to be more progressive than they actually are, especially by those who tend to focus on the top rather than the average rate and on individual rather than business taxes. This and related issues are discussed in Sections 3.2 and 3.3.

\subsection{Political Influence: The Lure of the Nordic Utopia}

Political influence is more difficult to measure than intellectual impact, because there is no obligation for politicians or voters to be systematic in their analysis. However, there is evidence that the Nordic model, if not precisely influencing American or British politics, has at very least provided a counterexample that could be used to refute attacks on "socialism" or the "welfare state" in usual political discourse. For the millennial generation, which 
has no memory of the Cold War, the redistributive or welfarist aspects of the Nordic model may actually constitute a positive aspect, particularly benefits such as free or reduced cost education, which have the most relevance to their lives. These are in addition to noneconomic policies, particularly environmentalism and women's rights, and the supposedly relaxed, healthy lifestyle that has come to be associated with the Nordic countries. ${ }^{6}$ This appeal persists, although at least one observer (Ohlsson (2006)) has argued that, with the collapse of the Soviet Union and local economic problems, the idea of Sweden and its neighbors as a "middle way" is hopelessly outdated.

The appeal of the Nordic model to millennials raises the question of reality and fantasy in political discourse. Relatively few Americans have traveled to the Nordic countries, and when they do, it is usually to a few places (Copenhagen, the Norwegian fjords) that are largely tourist-oriented. Almost no one speaks any of the Nordic languages, and when they do, they usually don't do so very well, resulting in a quick switch to English after the first exchange of pleasantries. There is an appetite for a few Nordic authors (Ibsen, Strindberg, Stieg Larsson) or filmmakers (notably Ingmar Bergman) but usually in translation and typically addressing universal rather than specifically Nordic themes. Notwithstanding the nostrum that "everyone speaks English" relatively few news sources are translated.

This lack of familiarity results in a blank canvas that is filled, to a large extent, by deliberate marketing efforts designed to create a positive image of the Nordic countries and their products. The most obvious example of this is commercial marketing. Whether it is Volvo popularizing the idea of automobile safety in the 1960s or 1970s, Lego or Minecraft emphasizing the idea of constructive play, or Skype and Spotify the idea of low-cost, cross-cultural communication, Nordic countries have consistently marketed themselves as humane, healthy, and just step ahead of everyone else in their advertising and product design. IKEA, which includes a child's playroom (Småland) in is stores and uses Swedish names for its products, is perhaps the ultimate example, although its founder left Sweden for 40 years to avoid high taxes. Nordic foreign policy, which frequently emphasizes human rights and develop-

\footnotetext{
6 For evidence of Norden's continuing political appeal, see text accompanying note 4 supra; Gardiner Harris, Obama Warms Up To Nordic Leaders, N.Y. Times, May 13, 2016, http://www.nytimes.com/20 16/05/14/world/europe/obama-warms-to-nordic-heads-of-state.html (U.S. President Obama invites five Nordic prime ministers to White House to discuss domestic as well as foreign policy issues)
}

ment assistance, may likewise be seen as a form of "branding” or marketing that enhances the region's image among younger, socially conscious consumers, although this is not its primary purpose.

Particularly important in Nordic marketing is the combination of progressive values with innovation and high technology. A principal objection to high taxes is that they discourage innovation and initiative, so that everyone will eventually wind up poorer than they were before (Blum and Kalven (1952)). But if this is true how can the Nordic countries, which have some of the world's highest tax rates, also be among the world's leading innovators? When one considers this issue systematically, there are of course various answers: that business taxes are really not so high in the Nordic countries; that several of the businesses in question are actually less innovative than first appears; that some of the key inventors have since left the region, some because of high tax rates; and so on. But the apparent combination of innovation and social consciousness is a heady mixture and may be more significant in explaining the attractiveness of the Nordic model than a room full or charts, graphs, or academic tomes.

It must be noted that praise for the Nordic utopia is matched by a large dystopian literature, often sponsored by conservative organizations anxious to discredit the Nordic model. Not surprisingly, taxes figure prominently in this literature. A blog sponsored by the American Enterprise Institute (AEI), a conservative think tank, features a post by James Pethokoukis with the catchy title "[i]f you want the Government to spend like a Nordic nation, it also needs to tax the middle class like one.” The post notes that Scandinavian (Nordic) tax systems were relatively flat in nature and concludes that “it wouldn't be just the rich paying for the progressive dream of greatly expanded Government, Scandinavian-style" but the middle (or at very least the upper middle) classes, as well. ${ }^{7}$ Pethokoukis has also published posts with titles including "7 myths about Scandinavia's social democratic 'paradise”' (July 6, 2015) and "Why America Can’t Be More Like Scandinavia" (October 30, 2012), addressing more general aspects of the Nordic Model. The latter argues that "the U.S. is about 30\% richer" than Sweden or Finland on a PPP basis and also more innovative, an argument which he supports with a graph showing that per capita patent filings increased in the United States during the period 1995-2010 but had actually decreased in the Nordic coun-

\footnotetext{
7 https://www.aei.org/publication/again-if-you-want-governmentto-spend-like-a-nordic-nation-it-also-needs-to-tax-the-middle-clas s-like-one/ (July 18, 2016)
} 
tries. ${ }^{8}$ The AEI is not alone: the Weekly Standard (Silberstein (2015)), a conservative journal, and even the liberal Washington Post (Booth (2015)) have published similar features, arguing that the Nordic countries are overtaxed, underperforming, and generally boring places that - to the extent they have performed well at all - have probably done so for cultural reasons rather than public policy.

While much dystopian literature originates in North America, the critics are not without support in the Nordic countries themselves. Prominent among these is the one by Nima Sanandaji, a Swede who writes books with titles such as "Debunking Utopia" and "Scandinavian Unexceptionalism," although he appears to be a biochemist by training rather than an expert on taxation or welfare policy (Sanandaji (2016); Sanandaji and Palmer (2015)). At least some of Sanandaji's criticisms are echoed in the work of Nordic and other social scientists who have studied their home countries in recent years (Sundberg (1993); Andersen (2007); Alestalo et al. (2009)). As a general rule, these critics do not suggest that the Nordic countries are unhappy or unsuccessful, but rather that they serious economic and political challenges and that the conditions for Nordic success would be difficult to replicate in other parts of the world. Scholars are also tend to distinguish between different countries and different time periods rather than lumping all of Norden together in one, undistinguished mass. Like the utopians, the dystopians exaggerate these arguments and take them out of context: indeed, the two concepts are a sort of mirror image of one another, a mix of reality and perception that is often most appealing to those with little direct experience of actual Nordic life.

\subsection{Tax Influence: Policy, Culture, and Administrative Reform}

The overall Nordic model, then, is attractive because of its seeming combination of economic prosperity and social justice or, in contemporary terms, of economic growth and innovation with a progressive, multicultural social outlook. The high taxes associated with this model are unpleasant, but justified by the benefits provided, and perhaps (to a certain kind of progressive) are a positive achievement in their own right. Even to conservatives, the prosperity and innovative spirit of the Nordic countries make the usual antitax arguments a little bit harder to

\footnotetext{
8 https://www.aei.org/publication/why-america-cant-be-more-like -scandinavia/. The principal source for this post appears to be Acemoglu et al. (2012), although the latter is somewhat more complex.
}

make or at very least require a more in-depth analysis of the societies in question: one cannot just dismiss them as glum dictatorships in the manner of Venezuela, Cuba, or the former Soviet Union.

Perhaps the most systematic scholarly treatment of Nordic taxes is Henrik Jacobsen Kleven, "How Can Scandinavians Tax So Much?” published in 2014. A professor of Danish origin now based in England, Kleven, suggests three principal answers to his own question. First, the countries in question make use of a large amount of third party information reporting, which makes tax evasion more difficult than it would otherwise be. Second, they have unusually broad tax bases, which (Kleven argues) results in a relatively low level of systematic tax avoidance. Finally, all three countries provide strong subsidies of goods that are "complementary to working," including child care, elder care, and transportation. These policies encourage a high level of participation in the work force by both women and men, which in turn generates more tax receipts. Interestingly, two of these three reasons relate to enforcement measures or tax design, and all three of them are institutional rather than attitudinal in nature, suggesting that at least some of the more attractive features of the Scandinavian tax systems might be transferable to other regions.

In a separate section of his paper, Kleven considers cultural factors more directly. While finding that Scandinavians share some attitudes that might explain their willingness to accept higher taxes, including relatively high levels of social trust, a high degree of civic engagement, and unusual sympathy for their poorer fellow citizens, he also suggests that such evidence is inconclusive and that it is difficult to tell whether these attitudes are a cause or a result of existing institutional arrangements Kleven (2014, 12-13). In any case, such factors would be difficult to transfer to the United States and other countries, whereas institutional arrangements are more likely to be exportable. Accordingly, the latter factors should be the principal lesson for tax reformers.

Kleven's paper is valuable, because it attempts to get beyond ideological differences and isolate aspects of Nordic taxation that might be attractive to reformers across the political spectrum. But it also captures the difficulties in evaluating the Nordic model of taxation, which involves a combination of factors that may be difficult to recreate in other circumstances. This is, of course, a common problem in comparative law that seeks to learn from the experience of other countries but runs up against irreducible cultural, historical, and geographic factors in doing so. This is true not only of deeply held values and attitudes, such as equality or women's rights, but also of institutional ar- 
rangements and even historical quirks that originate for obscure reasons but subsequently become embedded in a society's decision-making process.

In my research on progressive taxation, I found tax provisions to be highly resilient even when no one could remember the original reason for these provisions or when the reason no longer applied (Livingston (2006)). For example, agricultural income in India is taxable at the state rather than the national (union) level, an arrangement that apparently dates back to the British Raj and that has no particular reason or basis in Indian culture. Israel similarly inherited various tax rules from the British Mandate, including a near total exemption for overseas income, which remained in force for years after they had any real logic. One can argue that the entire Nordic model is itself a result of the region's peculiar historical and geographic circumstances, involving a number of small countries sandwiched between Nazi Germany and Soviet Russia, and might have turned out differently if one or more of these factors had been different. This does not mean that the Nordic model is irrelevant but suggests that one must be careful in evaluating another country or region's tax systems or in attempting to transfer parts of them from one location to another.

If an entire tax system cannot be imported from another country, what about bit and pieces? Three aspects of the Nordic tax model seem particularly exportable: administrative reforms (as suggested by Kleven), environmental and other social policy taxes, and the so-called "two-tier" system, in which capital is taxed at a rather lower rate than labor income. I will consider these items in turn.

\section{Administrative reforms}

While details differ from country to country, Nordic tax agencies have made significant strides in improving the efficiency of tax collection and (no less important) in transforming their image from enforcement agencies to something approaching the taxpayer's friend. The Swedish Tax Agency (skatteverket) is sufficiently proud of its reforms that it published a book, "From feared tax collector to popular service agency," that explains the changes and their philosophy in nontechnical language, complete with blue and gold diagrams and quotations from happy administrators and taxpayers (Stridh and Wittberg (2015)). The simplification of tax returns and the provision of quick, reliable telephone and online assistance are two of the major themes of the book. Other Nordic countries have adopted similar reforms: on a visit to the Danish tax administration (SKAT) in Copenhagen, I was shown a full room, appointed in contemporary Nordic furniture, that was devoted to answering taxpayer's inquiries, complete with charts and tables that measured each unit's efficiency in doing so.

Reforms of this nature are appealing to other countries, because they suggest improved efficiency in tax collection and (not coincidentally) an improved image for tax collection agencies. With this in mind, Nordic tax officials have made extensive presentations on local administrative reforms in other countries, including the United States. The idea of a simplified tax return, with taxpayer's entering basic information and the Government doing the rest, has attracted particular attention (Thompson (2016)).

One problem is that it may be difficult to separate administrative techniques from underlying issues of tax design and tax culture. For example, the Nordic countries require a level of transparency in financial transactions that could raise privacy objections in other regions. The heavy reliance on electronic transactions-many Swedish stores do not even accept cash payments-also makes information gathering easier than it may prove to be elsewhere. Even with these measures, tax avoidance may be higher than previously believed, as the Panama Papers scandal suggests. ${ }^{9}$ None of this means that there is nothing to be learned from the Nordic tax model, only that one must be careful about idealizing models of any kind and assuming that the more and less attractive features of a particular tax system can be separated from one another.

\section{Environmental taxes}

Carbon or similar taxes are another Nordic policy that has attracted attention in North America and other regions. Such taxes are attractive because - not unlike alcohol, tobacco, or other "sin taxes" - they both collect revenue and discourage socially harmful activities. The problem is making these taxes politically palatable in countries, such as the United States, which are both economically and, to a degree, psychologically dependent on fossil fuels. The Carbon Tax Center, which supports these policies, reports that only a small number of countries have enacted such taxes, none of them in North America and some countries repealing them after enactment. ${ }^{10}$. It is possible, however, that the Nordic countries are simply "ahead of the curve" on

9 See, for example, "Swedish FSA investigates Nordea after Panama Papers leak,” Reuters, Apr. 4, 2016, http://www.reuters.com/article/ us-panama-tax-nordea-idUSKCNOX10VT

10 See Carbon Tax Center: Where Carbon is Taxed, http://www. carbontax.org/where-carbon-is-taxed/ (Aug. 15, 2016) 
this issue. Canada is reported to be considering a tax of this nature, together with several of the more liberal American states - the Canadian province of British Columbia already has one - although a tax at the U.S. Federal level seems somewhat far off (McCarthy (2016)).

\section{Separation of Labor and Capital Tax Rates}

Perhaps the most frequently imitated aspect of Nordic taxation - although not necessarily one would the Nordic countries would like to take credit for - is the institution of a dual or multiple rate structure, with relatively higher rates on labor income and relatively lower rates on business or investment returns. In a sense, it is unfair to blame the Nordic countries for this concept that has existed from the beginning in the United States and most national income taxes. It must also be noted that American tax reform - for example, the Tax Reform Act of 1986 - has frequently involved the increase in business taxes in order to pay for the reduction of individual tax rates, that is, more or less the opposite of the Nordic model. But the real or imagined need to remain competitive in global markets has pushed many observers in the Nordic direction.

Republican Presidential candidate (now Presidentelect) Donald Trump recently unveiled a tax plan that would include a $33 \%$ maximum tax rate on individuals but a $15 \%$ rate on business income, together with trade and regulatory reforms that were designed to make the United States more competitive in international markets (Trump (2016)). Trump, who has populist pretensions, although he is usually regarded as a conservative, did not mention Scandinavia in his proposal. But it is interesting to see this aspect of Nordic taxation seeping consciously or unconsciously into the political discourse, and it is likely that we will see more of it in the future.

\section{Conclusion: Borrowing, Convergence, and the Limits of Globalization}

To this point, this paper has been largely descriptive, setting forth some of the essentials of Nordic tax policy and its appeal, or lack thereof, in other countries. But tax policy is a normative field, and readers like to see some positive recommendations at the end of a tax article. This following are a few attempts, together with a capsule review of themes developed in the article, and followed by some concluding thoughts on the Nordic model and implications for comparative law. While not all readers will agree with each of these conclusions, it is hoped that they will at least provide a basis for further debate and discussion:

1. Nordic tax policy is part of a larger "Nordic model" that includes an essentially capitalist economic system together with a universal welfare system and a relatively high degree of political and social consensus. Over time, this model has become associated with various noneconomic policies, including women's equality, a high degree of environmental consciousness, and a somewhat vaguer association with creativity, innovation, and a youthful cultural orientation. While facing significant internal challenges, the Nordic model has retained a substantial attractiveness to foreign observers, primarily but not exclusively on the political left, although it is unclear precisely which elements of the model are attractive and how much knowledge of Nordic reality is actually possessed by or even of interest to the admirers. The Nordic model also has numerous domestic and foreign critics, although this has not dented its appeal in progressive circles

2. Together with the more general Nordic model, there is a Nordic model of taxation that involves a relatively high and only modestly progressive individual income tax; significantly lower corporate, dividend, and capital gain taxes; and, increasingly, environmental taxes that have a pollution-reducing as well as a revenue-raising function. The Nordic countries are also characterized by a high degree of sophistication in tax administration, including extensive computerization and an at least theoretical emphasis on service to taxpayers as well as more traditional enforcement efforts. The relatively high level of tax compliance is in part a result of taxpayer attitudes, but in part of conscious institutional choices in tax administration and design.

3. The overseas appeal of the Nordic tax model is difficult to separate from the appeal of the model as a whole. While liberals are attracted by the potential for high revenues and (perhaps) the high tax rates themselves, conservatives are more skeptical, although intrigued by the model's apparent ability to sustain a high level of economic prosperity and (especially) technological innovation. Nordic advances in tax administration form a potential area of agreement between these groups, although these advances are themselves part of a Nordic tax culture that may be difficult to replicate elsewhere. Carbon 
or other environmental taxes are attractive to liberal politicians but have not yet penetrated the U.S. political mainstream. Other aspects of Nordic taxation, notably the existence of higher rates on labor than business or capital income, find expression in numerous countries but the Nordic influence on these policies is unclear.

4. While there is much to be gained from the study of Nordic tax systems, a degree of skepticism is in order, particularly regarding the systems' impact in North America. Although there is some serious study of the Nordic model, there is also a popular image of the Nordic countries as more egalitarian, innovative, and politically stable than they are in real life an image or fantasy that has been actively promoted by Nordic businesses and sometimes by the countries themselves. The assumption that Nordic taxes are more progressive than they actually are, or that the Nordic tax system can be separated from other aspects of the Nordic model, may be regarded as two related examples of this fantasy. This is not a condemnation of the Nordic countries per se but simply a recognition that the transfer or "borrowing" of tax and other legal provisions is a complicated business, and more fraught with danger than some observers may realize. Put differently, this paper provides a useful study of the potential for tax systems to learn from one another, but also of the inherent limitations of the learning process, and the danger that the experience of foreign countries will be applied in a selective manner to support a policy that is desired for other reasons.

5. Any discussion of Nordic tax policy must take into account the large and (in some cases) growing differences between the individual Nordic countries, which balance and frequently outweigh the similarities between them. The discussion must likewise consider the pressures for conformity to outside models, such as the European Union or the United States, and the Nordic reaction to these pressures, as well as the appeal of the Nordic model to these external actors.

All of this brings us back to globalization, perhaps the most overused word in contemporary scholarship but a useful term nonetheless. By definition, globalization involves the convergence of political and legal systems and the shrinking of distances between cultures..$^{11}$ In law, it

11 See http://sociology.emory.edu/faculty/globalization/issues01.ht $\mathrm{ml}$ (July 11, 2016), "Globalization broadly refers to the expansion of is associated with the concept of legal borrowing and of the so-called "legal transplants," that is, rules or institutions that originate in one culture and are adopted by (and adapted to) another (Watson (1993)). Indeed, one of the principal purposes of comparative law is to identify better approaches to the same or similar problems and (eventually) to apply them in one's own country. The very idea of a Nordic model is dependent on this logic.

But globalization carries dangers as well as opportunities. Cultures can be remarkably resistant to change, those that advertise their openness no less so than those which deny it. The desire to learn from other countries - or to use the experience of other countries in support of preexisting positions - can overwhelm our better judgment and lead us to incomplete or misleading conclusions. Even Swedes need subtitles to watch Danish TV. That doesn't mean that they shouldn't watch it, only that they should do so carefully.

\section{References}

Acemoglu, Daron, James A. Robinson, and Thierry Verdier, “Can't We All Be More Like Scandinavians: Asymmetric Growth and Institutions in an Interdependent World," NBER Working Paper No. 18441, October 2012, http://scholar.harvard.edu/files/jrobin son/files/varieties_of_capitalism_april_9_2013.pdf

Alesino, Alberto, Edward Glaeser, and Bruce Sacerdote, "Why Doesn't the U.S. Have a European-Style Welfare State," Harvard Institute of Economic Research: Discussion Paper No. 1933, Nov. 2001, http://post.economics.harvard.edu/hier/2001 papers/2001list.html

Alestalo, Matti, Sven E.O. Hort, and Stein Kuhne, "The Nordic Model: Conditions Origins, Outcomes, Lessons," Hertie School of Governance, Working Papers., No. 41, June 2009, https://www.hertieschool.org/fileadmin/images/Downloads/working_papers/41.pdf Anderson, Jenny, “Nordic Nostalgia and Nordic Light: The Swedish Model as Utopia, 1930-2007," 34 Scandinavian Journal of History 34(3): 229-245 (2009)

Andersen, Torben M., Bengt Holmström, Seppo Honkaphja, Sisten Korkman, Hans Tson Söderström, and Juhana Vartiainen, The Nordic Model: Embracing Globalization and Sharing Risks, Helsinki: ETLA, 2007

Blum, Walter J. and Harry Kalven Jr., "The Uneasy Case for Progressive Taxation,” University of Chicago Law Review 19: 417 (1952)

global linkages ... and the growth of a global consciousness, hence to the consolidation of world society." The website continues that "its [globalization's] meaning is disputed" and offers six alternate definitions emphasizing different aspects. Another website defines the term primarily in terms of economic integration prompting a Facebook comment "[and] [ l] eaving millions of workers with heartache," which the commenter attributes to Donald Trump, July 2, 2016. http:// www.merriam-webster.com/dictionary/globalization (July 11, 2016). 
Booth, Michael, The Almost Nearly Perfect People: Behind the Myth of the Scandinavian Utopia, London: Picador Press, 2016.

Booth, Michael, "Stop the Scandimania: Nordic nations aren't the utopias they're made out to be," (Jan. 16, 2015) https: //www.washingtonpost.com/opinions/stop-the-scandimanianordic-nations-arent-the-utopias-theyre-made-out-to-be/2015/ 01/16/8f818408-9aa0-11e4-a7ee-526210d665b4_story.html

Brandal, Nikolai, Øivind Bratberg, and Dag Einar Thorsen, The Nordic Model of Social Democracy, Basingstoke (UK): Palgrave Macmillan, 2013

Childs, Marquis, Sweden: The Middle Way, New Haven: Yale University Press, 1936

Dahlberg, Matz, Karin Edmark, and HeléneLundqvist, "Ethnic Diversity and Preferences for Redistribution," J. of Political Economy 1:120 (2012)

Henrekson, Magnus and Ulf Jakobsson, "Where Schumpeter Was Nearly Right: The Swedish Model of Capitalism and Capitalism, Socialism, and Democracy," J. Evol. Econ. 11: 331 (2001)

Hilson, Mary, The Nordic Model: Scandinavia Since 1945, London: Reaktion Books, 2008.

Kleven, Henrik Jacobsen, "How Can Scandinavians Tax So Much?" Journal of Economic Perspectives, 28(4): 77-98 (2014) http:// www.henrikkleven.com/uploads/3/7/3/1/37310663/kleven_jep _july2014.pdf

Kvist, Jon, Johan Fritzell, Bjørn Hvinden, and Olli Kangas (eds.), Changing Social Equality: The Nordic Model in the 21st Century, Bristol (UK): Policy Press, 2012

Livingston, Michael A., "From Milan to Mumbai, Changing in Tel Aviv: Reflections on Progressive Taxation and "Progressive" Politics in a Globalized But Still Local World," American Journal of Comparative Law, 54: 555 (2006)

Marklund, Carl and Klaus Petersen, "Return to Sender: American Images of the Nordic Welfare States and Nordic Welfare State Branding," European Journal of Scandinavian Studies, 43(2): 245-257 (2013)

McCarthy, Shawn, "Finance Canada eyes federal tax on carbon," The Globe and Mail, Jun. 12, 2016, http://www.theglobeandm ail.com/report-on-business/industry-news/energy-and-resource s/finance-canada-eyes-federal-tax-on-carbon/article30408215/
Ohlsson, Per T., "Sweden: Still the Middle Way?" talk at Columbia University, Sept. 28, 2006 http://www.columbia.edu /cu/swedish/events/fall06/ohlsson_flyer2.pdf

Partanen, Anu, The Nordic Theory of Everything: In Search of A Better Life, New York: HarperCollins, 2016

Rom-Jensen, Byron, The Mean Humane State: The Scandinavian Image in 1930s United States, Master's Thesis for Aarhus Universitet (June 2015) (copy on file with author).

Sanandaji, Nima, Debunking Utopia: Exposing the Myth of Nordic Socialism, Washington DC: WND Books, 2016

Sanandaji, Nima and Tom G. Palmer, Scandinavian Unexceptionalism: Culture, Markets and the Failure of Third Way Socialism, London: London Publishing Partnership, 2015

Scott, Andrew, Northern Lights: The Positive Policy Example of Sweden, Finland Denmark and Norway, Melbourne: Monash University Publishing, 2014

Silberstein, Benjamin Katzeff, "Sorry Leftist Americans, Your Swedish Utopia Does Not Exist," Weekly Standard (Jul. 30, 2015) http://www.weeklystandard.com/sorry-leftist-americans-yourswedish-utopia-does-not-exist/article/1000785

Stridh, Anders and Lennart Wittberg, "From feared tax collector to popular service agency," Skatterverket (Swedish Tax Authority) (2015)

Sundberg, Jacob, "Revenue-only taxes vs. multipurpose taxes: philosophy and intimidation in Swedish high tax society," in Gerard Radnitzky and Hardy Bouillon (eds.) Government: Servant or Master (Amsterdam: RodopiBv Editions, 1993

Thompson, Derek "The Ten Second Tax Return," Atlantic Magazine (Mar. 30, 2016) http://www.theatlantic.com/business/archi ve/2016/03/the-10-second-tax-return/475899/

Trump, Donald J., “An America First Economic Plan: Winning The Global Economic Competition," Text of Speech to the Detroit Economic Club, Aug. 8, 2016, https://www.donaldjtrump.com/pressreleases/an-america-first-economic-plan-winning-the-global-co mpetition

Watson, Alan, Legal Transplants: An Approach to Comparative Law $\left(2^{\text {nd }}\right.$ ed.) Athens (GA): University of Georgia Press, 1993 